\title{
Impact of firm size on the Weekend effect: The Australian Stock Exchange evidence
}

\author{
Saqib Sharif ${ }^{1}$
}

\begin{abstract}
This paper examines whether the Weekend effect anomaly documented in the extant literature exists in the Australian Financial Exchange (ASX). Daily data from January 1994 to September 2018 documents a strong Weekend effect in equal-weighted index and small firms before the Global Financial Crises (GFC). That is, as the size of the business increases the Weekend effect starts to dissipate due to significantly negative Monday returns for small-capitalized firms and significantly positive Monday returns for large-capitalized firms. On the other hand, during and after the GFC period, from January 2008 to September 2018, this study finds strong Weekend effect in large capitalized stocks and weakly significant effect in small capitalized stocks. Hence, the evidence suggests that Weekend effect still persist for Australian securities, but have shifted from smaller stocks to larger stocks. Moreover, this study finds absence of Weekend effect in equal-and value-weighted indices in the 10-year recent data. Therefore, investing in stock index futures contracts would not yield better returns due to diminishing of Weekend effect anomaly in indices
\end{abstract}

\section{JEL Classification: $G 10, G 12, G 14$.}

Keywords: Weekend effect, Australian Stock Exchange (ASX), Stock returns, Size effect, Efficient Market Hypothesis (EMH).

\section{INTRODUCTION}

Researchers have investigated the stock market calendar anomaly of Weekend Effect for more than four decades. The literature comprises, for example, French (1980), Gibbons \& Hess (1981), Jaffe \& Westerfield (1985), Lakonishok \& Maberly (1990), Abraham \& Ikenberry (1994), and Caporale, Gil-Alana, \& Plastun (2016). The difference between the Friday returns and the next week Monday returns is called the Weekend Effect. Evidence from abovementioned papers concludes that security returns on Friday are positively significant and larger compared with the rest of trading days of the week, whereas security's Monday returns are substantially negative and lesser, compared to rest of trading days of the week. Conversely, Connolly (1989) claim that the Weekend Effect anomaly is unsustainable over the extended period, it exists in certain time periods, fades in some periods and re-emerge again. Moreover, the study of Brusa, Liu, \& Schulman (2000) finds a significantly 'reverse' or negative Weekend Effect - that is, security returns on Monday are considerably positive and greater than the rest of trading days of the week, especially from the early nineties in medium and large-cap stocks.

This study extends the boundaries of existing literature in numerous ways. Firstly, the paper investigates whether the Weekend Effect anomaly observed in the extant literature subsists in the Australian exchange. Secondly, this paper documents the association between the Weekend effect and firm size. Thirdly, this research utilizes recent data to explore the Weekend effect anomaly in one of the developing markets, since recent studies mainly focus

\begin{tabular}{lccc}
\hline 1- & Department of Finance, Institute of Business Administration (IBA), & Main Campus, Karachi. Email: ssharif@iba.edu.pk \\
\hline JISR-MSSE & Volume 17 & Number 1 & January-June 2019 165
\end{tabular}


on emerging markets to test this trading anomaly (e.g., Akbalik \& Ozkan, 2017). The results in the paper exhibits a strong Weekend Effect in equal-weighted index, whereas no Weekend Effect is observed for value-weighted index during January 1994 through December 2007 sample period. Even after bifurcating the whole sample into two equally spaced sub-samples, the Weekend Effect exists over time in the equal-weighted index but is non-existent in value-weighted index. However, when this paper examines the Weekend Effect by year i.e. dividing the whole sample into yearly data, the paper depicts the Weekend Effect is non-sustainable anomaly over a long period, especially in the recent past. Nevertheless, the recent 10-year daily data from January 2008 to September 2018 shows renewed weekend effect for larger firms compared to smaller firms. The evidence of this paper confirms the findings of Connolly (1989) who finds that this trading anomaly disappears in certain periods and reappears again. Similarly, Rossi \& Gunardi (2018) does not find consistent calendar anomalies for four European markets, especially after the first decade of new millennium and mention that weekend effects are country-specific due to difference in market environments.

Further, after establishing the robust Weekend Effect in equal-weighted index only, this study analyses the Weekend Effect by ranking the portfolio of stocks into size quintiles on the basis firms' market value, by rebalancing the portfolios each year. Market capitalization is defined as daily close price times the outstanding number of ordinary shares. Consistent with Brusa et al. (2000), this study finds the smallest size (first quintile) portfolio exhibits significantly strong Weekend Effect and the largest portfolio of stocks (fifth quintile) exhibit a rather weak reverse or a negative Weekend Effect from 1994 to 2007 (i.e., before the GFC). Whereas, for the period 2008 to 2018 , this study finds weakly significant Weekend effect for smallest size quintile firms and strong impact for largest size quintile firms. Hence, for the pre-GFC period as the firm size increases the average Weekend Effect starts to dissipate and even becomes the reverse of the expected result. The post-GFC period shows strong Weekend effect for the large-cap firms. Lastly, the findings of disappearance of trading anomaly in the indexes is consistent with the study of Olson, Mossman, \& Chou (2015) who finds emergence of weekend effect and its subsequent disappearance as investors exploit such kind of anomalies / profit opportunities and drives away its effect.

The rest of the paper is structured as follows. Section 2 discusses the literature review. Section 3 explains the data and the methodology of the study. Section 4 discusses the empirical results, and Section 5 concludes this study.

\section{LITERATURE REVIEW}

\section{Efficient Market Hypothesis}

The theory of "Efficient Capital Markets" suggests the information that is readily available to investors is incorporated in the security prices of the specific scrips and the financial exchange as a whole. Hence stocks are fairly valued, as the news spreads without interruption and is reflected instantly into the security prices. Fama (1970) claims that no trader can consistently outperform the market or generate more than the market returns. Similarly, Malkiel (2003) holds that information by classification is unpredictable, and hence, subsequent changes in stock prices must be random. Thus Malkiel (2003) believes that the efficient financial market hypothesis is connected with the theory of a random walk, a terminology used vaguely that highlights a price series with subsequent changes in security price signify random departures from prior prices. Hence, talking about efficient market, we assume that the returns on each

166 January-June $2019 \quad$ Volume $17 \quad$ Number 12 JISR-MSSE


day-of-the-week would yield similar returns on average. In this context, Dellavigna \& Pollet (2009) compared earnings announcements of Friday with other weekdays to gauge investor reaction on stock returns.

The idea of market efficiency has some repercussions as well, as to whether stock prices are set at a reasonable level and how prices shift. However, while the facts by and large depict that prices do not reveal past information, this is not always the case and hence opens the window of chance for analysts and investors to make the right moves. For example, a study by Fama \& French (1988) describes that contingent on the forecast horizon, the variance of future returns up to $40 \%$ for the stock exchange can be estimated based on initial dividend yield of the exchange.

Moreover, the pricing of firm size remains one of the more challenging subjects for the supporters of efficient financial market hypothesis and traditional capital asset pricing model CAPM). According to the CAPM, 'beta' is the proper determinant of risk for a stock, such that the security return varies with the change in the structure of whole stock market. Fama \& French (1993), examining data from 1963 to 1990 and dividing all securities into deciles ranked by their market capitalization, find a perfect trend for the smaller firms' deciles portfolio to generate greater monthly returns as compared to deciles of larger firms portfolio. However, if beta is considered the right reflection of market-wide risk from the model of capital asset pricing (CAPM), then the effect of size can be counted as an anomaly that contradicts efficient market theory.

An another study by Fama \& French (1992) show that investing in a portfolio of stocks ranked by the book-to-market ratio also yields different annual returns. Likewise, Caporale et al. (2016) finds empirical evidence of weekend effect in the Ukrainian futures market and shows that investors earn up $25 \%$ annual returns by exploiting this trading anomaly. Thus, Caporale et al., propose that Ukrainian capital market is inefficient.

Yakob, Beal, \& Delpachitra, (2005) test the seasonal effect in a group of Asia-Pacific countries i.e., holiday anomaly, monthly anomaly, month-of-the-year anomaly, and day-of-the-week effects. The authors find different calendar patterns in different markets. But they are of the opinion that significant returns do not transform into windfall gains and hence applicability of efficient market hypothesis $(\mathrm{EMH})$ cannot be disputed while considering the transaction costs.

\section{US Evidence on Weekday and Weekend Effect}

The study of Gibbons \& Hess (1981) explores the day-of-the-week calendar anomaly. The authors note that scientists largely assume that distributional characteristics of stock returns is similar for all trading days of the week - a requirement for market equilibrium. Gibbon \& Hess (1981) examine stock returns for day-of-the-week anomaly on three indexes; the S \& P 500 and the value-weighted and equal-weighted portfolios developed by the CRSP. The authors find an economically significant mean negative returns for Monday across individual securities and lower or below-average returns on sovereign treasury bills on Mondays. In the same study Gibbon \& Hess (1981) examined the influence of day-of-the-week effects on tests of market efficiency. The authors find that market-adjusted returns display the day-of-the-week effect, but the impact is not concentrated on any specific day-of-the-week.

\begin{tabular}{lllll}
\hline JISR-MSSE & Volume 17 & Number 1 & January-June 2019
\end{tabular} 
Besides, Chkir et al. (2014) investigated weekday effect in currency markets but does not find empirical irregularity in the day-of-the-week-effect for ready / spot foreign currency rates.

Moreover, Mehdian \& Perry (2001) re-assessed the Monday anomaly / effect in five major United States equity indexes - the Standard \& Poors 500 (S\&P 500), the New York Stock Exchange (NYSE) composite, the Dow Jones composite (DJCOMP) representing large firms; the Russell 2000 (RUSSELL), and the NASDAQ composite representing pre-dominantly the smaller firm securities. The time period of their study covers June, 1964 through February 1998. The major finding of Mehdian \& Perry (2001) study is that the observed Monday effect is unsteady and considerably time-shifting throughout the trading data under consideration. Especially following the 1987 crash, the authors find that: 1) first trading day (i.e., Monday) returns are substantially positive and smaller than rest of trading days of the week, and 2) Monday returns are similar to rest of the trading days of the week for three indexes i.e., S\&P 500 , NYSE, and DJCOMP. However, their study observes Monday returns for two indices i.e., NASDAQ and the RUSSELL considerably smaller than rest of trading days of the week.

Keeping in view the efficient market theorem, French (1980) tests the two hypotheses for the time period 1953 through 1977 i.e., trading time and calendar time hypothesis with the method generating stock returns by comparing each day-of-the-week returns of Standard and Poor's (S\&P) composite portfolio. However, the findings of French (1980) are contrary to both the assumed models. He finds negative Monday returns, whereas positive returns observed for the rest of four days of the week. Among the remaining four trading days i.e. Tuesday till Friday, the Friday returns are largest and significantly positive. This phenomenon is called 'Weekend Effect' or 'Monday effect'. Moreover, French (1980) contends that the presence of the Weekend Effect may be an implication for market efficiency; perhaps, the idea is that companies do not release the bad news during the weekdays due to fear of selling pressure and hold the information until the weekend in order that investors may able to assimilate it.

Keim \& Stambaugh (1984) investigate the Weekend Effect further by adding additional stocks and lengthening the sample period to 55 years as compared to the French (1980) study. The authors reveal negative first trading day returns (i.e., either Mondays or Tuesdays) for the whole period. Besides, they find a high correlation between last trading day and the following first trading day returns as compared to other successive days' correlation on the Dow Jones 30 Index portfolio.

Similarly, Abraham \& Ikenberry (1994) in their study investigating the causes of the existence of the Weekend Effect using CRSP equal-weighted index returns during 1963-1991, find a strong relationship between Fridays and Mondays return; particularly Mondays return are negative $80 \%$ of the time when Fridays return are also negative. However, Olson et al. (2015) finds that weekend effect disappears when it was first discovered by the researchers and academics in 1973, but thereafter its effect and magnitude went through the periods of reappearance and even reversal.

Brusa, Liu, \& Schulman (2000) re-assessed the Weekend Effect to explore whether after more than 20 years under the spotlight, the Weekend Effect still subsists or has disappeared in US markets. Their sample period includes five years of data January 1, 1990 through December 31, 1994 - in four major security indexes: the value weighted CRSP, the DJIA index, the NYSE index, and the S\&P 500 index. The authors breaking the CRSP firms into decile

168 January-June $2019 \quad$ Volume $17 \quad$ Number $1 \quad$ JISR-MSSE


portfolios by sorting firms' market capitalization observed that the Weekend anomaly is linked to the firm size. They find evidence of the Weekend Effect in portfolio of smaller firms but a weak negative or 'reverse' Weekend Effect is observed in medium size firms and a strong negative or reverse Weekend Effect appears in larger firms.

Hence Brusa et al. (2000) find that the disappearance of the Weekend Effect in medium and large size firms is mainly because of Monday returns which increased steadily from significantly negative values for smallest firms to significantly positive values for largest firms. This causes a new phenomenon of 'reverse' Weekend Effect to appear in largest firm securities of US equity markets. This study, investigating the Weekend Effect in Australian listed stocks, also find different results for pre- and post-GFC period, i.e., during 1994-2007, the small-cap stocks have a significantly strong Weekend Effect and large-cap stocks have a weakly significant negative Weekend Effect. Whereas, during 2008-2018, small firms show weak effect and large-cap firms show strong weekend effect.

\section{International Evidence on Weekday and Weekend Effect}

The share exchange seasonality or day-of-the-week anomaly still catches the interest of researchers owing to the generation of abnormal or significant returns during certain time periods. The study by Yakob et al. (2005) is carried out to test holiday, monthly, month-of-the year, and day-of-the week effects in select countries of Asia Pacific. Since the major focus of current study is on the Weekend Effect; thus only the day-of-the-week anomaly is looked at. In their sample, out of ten countries, five show a presence of day-of-the-week anomaly for the period under consideration. Indonesia depicts the Monday effect. Australia and Taiwan show the existence of significant Friday returns or Friday effect. Moreover, the robust positive (largest) Friday and negative (lowest) Tuesday effect is documented in the study of Davidson \& Faff (1999) on Australian market

Similarly, the study of Easton \& Faff (1994) tests the strength of the day-of-the-week anomaly in Australia. The data comprises of closing daily prices of the Sydney Stock Exchange Statex-Actuaries Price and Accumulation Indices during 1974-85 period. The authors find a robust positive (largest) Thursday and significantly negative (lowest) Tuesday effect / returns in the Australian stock market. Besides, Akbalik \& Ozkan (2017) studied benchmark indexes of five countries, i.e., Brazil, India, Indonesia, Turkey, and South Africa (BIITS) after the US sub-prime mortgage and Global Financial Crisis of 2007-08. They find day-of-the-week anomaly is absent in emerging markets, except Indonesia. In Indonesia, Akbalik \& Ozkan find significantly negative first trading day (i.e., Monday) returns and positive Wednesday returns.

Several researchers examine the Weekend Effect in non-U.S. markets, as it still catches the attention of academicians and practitioners owing to the generation of abnormal or significant returns during certain time periods. Hence the research paper by Board \& Sutcliffe (1988) examines the Weekend Effect in United Kingdom by analysing the Financial Times All Share Index (FTSE-All) data. The data comprises of daily closing index points / values of the FTSE-All index April 1962 through April 1986 i.e. 24-year study period. The authors find clear support for the Weekend Effect, but with the significance of the effect decreasing over time. Further, they observe Mondays' return variance marginally higher than rest of trading days of the week, signifying that the speed of momentum returns generating method slows down considerably over the weekend.

\begin{tabular}{llll}
\hline JISR-MSSE & Volume 17 & Number 1 & January-June 2019 \\
\hline
\end{tabular}


Another study by Jaffe \& Westerfield (1985) explores the Weekend Effect in equity returns in four different countries i.e., Australia, Canada, Japan, and United Kingdom., and. The authors collected daily returns data for the financial exchange indices of four countries and the United States; and claim that these five economies account for roughly $87 \%$ of the global market capitalization of exchange listed debt and equity securities. The authors find the Weekend Effect in all four countries. But contradicts previous research work on the U.S. market, the lowest average returns on Tuesday are observed for both the Australian and Japanese financial exchanges.

\section{Explanations of the Weekend Effect}

Under ordinary conditions, seasonality means share markets are not informationally efficient. This suggests that some other trading strategies cause this seasonality pattern or day-of-the week effect (Yakob et al., 2005). Besides, the behavioural aspect of individual or institutional investors may also be one of the many reasons of the Weekend Effect anomaly. Hence many probable reasons of the Weekend Effect were offered and explored: French (1980) suggests that the most understandable cause of the Weekend Effect is that the release of material information over the weekend is likely to be adverse and hence companies postpone the release of news until the weekend due to fear of panic selling, allowing additional time to investors for the news to be absorbed.

In another study, Keim (1989) investigates the observed Weekend Effect in National Market System (NMS) of NASDAQ - the digitized system providing extra market information, including day-end bid prices and ask prices as well as day-end data on transaction prices of securities. Earlier studies like Keim \& Stambaugh, (1984) assume that the trend for trading transactions to close at the ask prices on Fridays and at the bid prices on Mondays may partially describe the negative Monday returns. By means of NMS data for the period from 1983 to 1987, Keim (1989) find that the bid-ask spread jump account for one-third or 32 percent of the documented Weekend anomaly, simply for low-priced shares (i.e., penny stocks) or smaller firms.

Lakonishok \& Maberly (1990) find that retail investors trade relatively more than institutional investors on Mondays in the NYSE listed common stocks covering the period from 1962-86. The authors believe retail traders have more time to plan during the weekend and thus trade more aggressively on Mondays, whereas the institutional investors start their tactical planning on Monday and hence are less active. Thus selling pressure on Mondays and subsequent negative returns provide a fractional justification of the Weekend Effect anomaly. Similarly, Abraham \& Ikenberry (1994) find active selling of stocks by individual investors especially following a bad news in the market. The authors also verify that selling pressure is not only greater on first trading days of the week (i.e., Mondays) but considerably significant following a negative close on previous Fridays. Further, Abraham \& Ikenberry (1994) observe that buy related information is released during trading hours/days, whereas sell related information is released during weekend. Thus trading strategies of individuals at least in part is responsible or provides explanation for the observed anomaly (the Weekend Effect).

Chen and Singal (2003) proposes the role of speculative short sale traders as partial explanation of the Weekend Effect phenomenon observed in United States financial markets. However, the studies of Blau, Ness, \& Ness (2007) and Christophe, Ferri, \& Angel (2009)

170 January-June $2019 \quad$ Volume $17 \quad$ Number $1 \quad$ JISR-MSSE


which investigate the Weekend Effect in NYSE intraday data and NASDAQ intraday data respectively, find that customer (speculative) short sale does not clarify the meaningful percentage of the Weekend Effect, that is contrary to Chen and Singal (2003) hypothesis. Similarly, Gao, Hao, Kalcheva, \& Ma (2015) investigating the Chen and Singal hypothesis in the Hong Kong Stock Exchange (SEHK), does not find support for the hypothesis.

Nevertheless, Yakob et al. (2005) are of the view that researchers need to devise trading strategies which can provide abnormal returns after incorporating the transaction costs which may negate the efficient capital market hypothesis (EMH). They caution that meaningful returns do not translate into windfall gains and hence does not disprove the applicability of EMH.

\section{DATA \& METHODOLOGY}

Daily data are obtained from the Securities Industry Research Centre of Asia-Pacific (SIRCA), which is an Australian based research organization. The sample consists of all stocks which traded at least 125 days or more on the Australian Securities Exchange (ASX) in each year from January 1994 to September 20018.1 The equally weighted index returns are calculated by SIRCA. Value-weighted index, Sector indices, and Size and Style indices prices/values are downloaded from the Global Financial Database website because SIRCA only has the value-weighted data starting from the year 1998. The closing price is the adjusted end of day close price (adjusted for dividends and stock splits etc). The daily returns are defined as in equation (i):

$$
\mathrm{R}_{\mathrm{t}}=\ln \left(\mathrm{Pt}_{\mathrm{t}} / \mathrm{Pt}_{\mathrm{t}-1}\right) \times 100
$$

Where $\mathrm{Rt}$ is the return observed on day $\mathrm{t}$, $\mathrm{Pt}$ is the closing price/value of the stock/index observed on day $\mathrm{t}$, and Pt-1 is the closing price/value of the stock/index observed on the prior trading day.

The market capitalization (size) is calculated as in equation (ii):

$$
\text { Market Capitalization }=\text { Closing Price } \times \text { Number of Shares Outstanding }
$$

The portfolios are rebalanced every year and then merged with one of the quintile portfolios; 1 being the smallest and 5 being the largest size quintile portfolio of firms.

Table 1, Panel A presents descriptive statistics of the stocks used in the analysis and Panel B presents average quintile levels for the stock characteristics. The average stock in our sample has a price of AU $\$ 4.634$ with daily market capitalization and daily trading volume of AU $\$ 784,482,464$ and 604,863 . The Market capitalization is calculated by multiplying closing price with a number of shares outstanding. The minimum price of a stock in the sample is AU\$0.001 and the maximum price is AU\$2,421.

When the sample of ASX-listed stocks is compared with the study of Blau et al. (2007) of NYSE-listed stocks (US market), it is observed that the average price of the NYSE-listed stocks is US\$33.04, (as compared to this study average stock price of AU\$4.634) which indicates that a majority of ASX listed firms are relatively small. Panel B reports the descriptive statistics by average quintile. The Weekend Effect is defined as the difference

\begin{tabular}{llll}
\hline JISR-MSSE & Volume 17 & Number 1 & January-June 2019 \\
\hline
\end{tabular}


between Friday returns and the following Monday returns. A t-test (sign rank test) is used to examine whether the mean (median) is different from zero for the Weekend Effect. That is, whether the Friday returns are significantly different from Monday returns? After analyzing the returns for Mondays, Fridays, and weekend and their p-values on the whole dataset, the dataset has been split into different sub-periods to investigate the persistence of calendar anomaly.

Table 1 depicts summary statistics of securities in our sample. For a security to be chosen for the sample, it must have traded 125 or more days each year on the ASX. The sample time period is daily data from January 01, 1994 to September 30, 2018. The statistics are presented for price in Australian Dollars, market capitalization in Australian Dollars, average daily trading volume. Price is the daily last transaction (i.e., closing price) for each security, daily market value / capitalization is measured as close price multiply by number of common shares outstanding.

Table 1. Descriptive Statistics of Stocks

\begin{tabular}{|c|c|c|c|}
\hline \multicolumn{4}{|c|}{ Panel A: Summary Statistics } \\
\hline & Price & Daily Market Capitalization & Average Volume \\
\hline Mean & $\$ 4.634$ & $784,482,464$ & 604,863 \\
\hline Median & $\$ 0.700$ & $49,135,226$ & 87,749 \\
\hline Std dev & $\$ 23.291$ & $3,996,513,800$ & $3,443,849$ \\
\hline Min & $\$ 0.001$ & 36 & 1 \\
\hline Max & $\$ 2,421$ & $166,293,700,000$ & $1,911,951,074$ \\
\hline \multicolumn{4}{|c|}{ Panel B: By Average Quintiles } \\
\hline & Price & Daily Market Capitalization & Average Volume \\
\hline Quintile V & 20.228 & $3,654,591,856$ & $2,626,255$ \\
\hline Quintile IV & 1.900 & $192,301,962$ & 272,304 \\
\hline Quintile III & 0.730 & $52,474,497$ & 90,376 \\
\hline Quintile II & 0.246 & $17,804,418$ & 29,773 \\
\hline Quintile I & 0.063 & $5,226,456$ & 5,523 \\
\hline
\end{tabular}

\section{RESULTS}

The results are presented in three sections. First Weekend Effect is investigated, that is, whether the Friday return is larger than the next week Monday's return on value-weighted and equal-weighted indices. In the second section, the Weekend Effect is explored on certain broad indices on the basis of sectors, size and style in order to ascertain whether the economic events cause Weekend Effect that might affect all the economic sectors across the board or it is a sector-specific phenomenon or is a manifestation of market capitalization (size) factor. Finally, in the third section, the Weekend Effect on the basis of firm size is investigated to confirm the results obtained in Table 2 .

\section{The Weekend Effect}

The methodology of Chen and Singal (2003) is adopted in this section to test the Weekend Effect. Here Friday is considered the last trading day-of-the-week, either it is a Thursday or a Friday. On the same lines, Monday is considered the first trading day-of-the-week, either it is a Monday or a Tuesday.

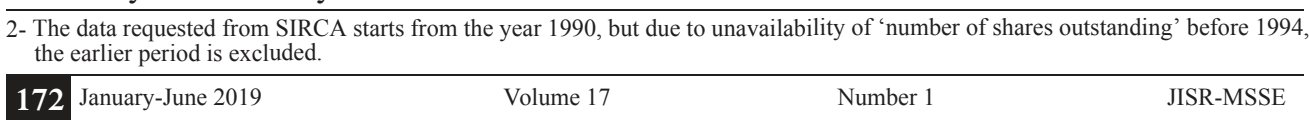


The study sample comprises all stocks listed and traded on ASX (i.e., those securities that have been traded at least 125 days or more in each year from 1994 to 2018 are included). The equally weighted returns (in percent) are provided by SIRCA; whereas the value weighted index returns have been measured by us (i.e., $\ln (\mathrm{pt} / \mathrm{pt}-1)$ closing to closing prices/index value of each day). Monday is the first trading day-of-the-week, either it is a Tuesday or a Monday while Friday is the last trading day-of-the-week, either it is a Thursday or a Friday. The Weekend Effect is the difference between a Friday's return and the next week Monday's return. The p-values for examining the mean (median) difference between the last and first trading day returns obtained through t-test (signed-rank test) are displayed in parenthesis.

Table 2: The Weekend Effect

\begin{tabular}{|c|c|c|c|c|c|}
\hline \multirow{2}{*}{ Panel A: 1994-20C } & \multicolumn{2}{|c|}{$\begin{array}{l}\text { Equally weighted } \\
\text { index return }\end{array}$} & \multicolumn{2}{|c|}{$\begin{array}{l}\text { Value-weighted } \\
\text { index return }\end{array}$} & \multirow[t]{2}{*}{$\begin{array}{l}\text { Number } \\
\text { of days }\end{array}$} \\
\hline & & & & & \\
\hline & Mean & Median & Mean & Median & \\
\hline \multirow[t]{2}{*}{ Monday } & -0.0982 & -0.0490 & 0.0260 & 0.0721 & 726 \\
\hline & $(<.0001)$ & $(0.0015)$ & $(0.0231)$ & $(0.0115)$ & \\
\hline \multirow[t]{2}{*}{ Friday } & 0.0767 & 0.0930 & 0.0026 & 0.0230 & 726 \\
\hline & $(<.0001)$ & $(<.0001)$ & $(0.4256)$ & $(0.4607)$ & \\
\hline \multirow[t]{2}{*}{ Weekend Effect } & 0.1749 & 0.1680 & -0.0234 & -0.0040 & 726 \\
\hline & $(<.0001)$ & $(<.0001)$ & $(0.5878)$ & $(1.000)$ & \\
\hline \multicolumn{6}{|c|}{ Panel B: Sub-periods } \\
\hline \multicolumn{6}{|l|}{ 1994-2000 } \\
\hline \multirow[t]{2}{*}{ Monday } & -0.0865 & -0.0340 & 0.0088 & -0.0003 & 362 \\
\hline & $(0.0046)$ & $(0.0920)$ & $(0.2631)$ & $(1.000)$ & \\
\hline \multirow[t]{2}{*}{ Friday } & 0.1324 & 0.1720 & -0.0068 & -0.019 & 362 \\
\hline & $(<.0001)$ & $(<.0001)$ & $(0.7993)$ & $(0.5633)$ & \\
\hline \multirow[t]{2}{*}{ Weekend Effect } & 0.2189 & 0.2100 & -0.0156 & 0.0200 & 362 \\
\hline & $(<.0001)$ & $(<.0001)$ & $(0.8142)$ & $(0.7933)$ & \\
\hline \multicolumn{6}{|l|}{$2001-2007$} \\
\hline \multirow[t]{2}{*}{ Monday } & -0.1116 & -0.0640 & 0.0432 & 0.0941 & 364 \\
\hline & $(<.0001)$ & $(0.0051)$ & $(0.0277)$ & $(0.0114)$ & \\
\hline \multirow[t]{2}{*}{ Friday } & 0.0208 & 0.0380 & 0.0119 & 0.0211 & 364 \\
\hline & $(0.0206)$ & $(0.0306)$ & $(0.3796)$ & $(0.6390)$ & \\
\hline \multirow[t]{2}{*}{ Weekend Effect } & 0.1324 & 0.1230 & -0.0313 & -0.0270 & 364 \\
\hline & $(<.0001)$ & $(<.0001)$ & $(0.5702)$ & $(0.7928)$ & \\
\hline \multirow[t]{2}{*}{ 2008-2018 } & S\&P/ASX Ec & & S\&P/ASX Va & & \\
\hline & Weighted In & & Weighted In & & \\
\hline \multirow[t]{2}{*}{ Monday } & -0.0099 & -0.0073 & -0.0116 & 0.0091 & 487 \\
\hline & $(0.1625)$ & $(0.1123)$ & $(0.1897)$ & $(0.3628)$ & \\
\hline \multirow[t]{2}{*}{ Friday } & -0.0236 & 0.0548 & -0.0391 & 0.0239 & 487 \\
\hline & $(0.2817)$ & $(0.0729)$ & $(0.4852)$ & $(0.0413)$ & \\
\hline \multirow[t]{2}{*}{ Weekend Effect } & -0.0136 & 0.0621 & -0.0275 & 0.0148 & 487 \\
\hline & (0.8389) & $(0.8690)$ & $(0.6787)$ & $(0.8758)$ & \\
\hline
\end{tabular}

Panel A of Table 2 covers the period from 1994 to 2007; in the first two columns under equally weighted index return, it is observed that the returns on the first trading day of week (i.e., Monday or Tuesday) are significantly negative and the returns on the last trading day of the week (i.e., Friday or Thursday) are significantly positive. Resultantly, the positive Weekend 
Effect persists for full-sample weekends and is strongly statistically significant for both mean and median values of equally weighted index: 0.17 percent for the mean Weekend Effect and 0.16 percent for the median Weekend Effect with p-values less than 0.01 . On the other hand, the two columns under value-weighted index return (i.e., the index representing the large firms) depict a totally different picture i.e., Monday's return is significantly positive. Whereas, the Friday's return is not statistically significant. As a result, inconclusive or insignificant negative / reverse Weekend Effect is witnessed. Chen and Singal (2003) find the evidence of a positive Weekend Effect in both the equal- and value-weighted index covering the study sample period 1962 through 1999 in United States market. Whereas, this study finds Weekend Effect only in equal weighted index (i.e., index that give equal weight to all firms, irrespective of the size) which is 0.17 percent compared to 0.34 percent in their findings.

To scrutinize whether the Weekend Effect persists across time, we bifurcate the sample into two equally spaced sub-periods: 1994-2000 and 2001-2007 and then recent 10-year period 2008-2018. Panel B of Table 2 shows the analysed results. Though the Weekend Effect for the equal weighted index stays unabated throughout the two sub-periods, the mean Weekend anomaly for the value-weighted index is negative but insignificant. The other interesting thing we detect in Panels A and B of Table 2 (sub-period of 2001-07) is that the Monday return is significantly positive under value-weighted index and due to this the Weekend Effect disappears. Similarly, in the third sub-period between 2008 to 2018, the weekend effect disappears for both the equal- and value-weighted indexes.

The insignificant negative Weekend Effect in the last / recent sub-period under value weighted index confirms the evidence of Chen and Singal (2003). They distributed the whole sample into three sub-periods. Their study shows an insignificant negative mean Weekend Effect / calendar anomaly in value weighted index for the third sub-period i.e., 1990-1999. Hence the overall findings of Table 2 suggest that the positive or negative Weekend Effect are driven by some risk or behavioural explanation linked to the firm size which will be further explored in the later section of this study. However, the plausible justification for absence of weekend effect for value-weighted index is that the constituent companies have higher free-float (i.e., very liquid) and large, such firms are widely held by institutions \& retail investors, and widely followed by market analysts. Thus, for such kind of stocks, typically the market anomalies does not hold, consistent with the studies of Akbalik \& Ozkan (2017) on stock indexes of emerging markets and Olson et al. (2015) on stock indexes of US markets.

\section{The Weekend Effect in Various Sector and Size Indices}

To check the prevalence of Weekend Effect in different sectors, we looked at the daily returns of ten indices constituting of various economic sectors like energy, retail, finance, health care, industries, materials, telecommunication, transport, consumer, and utilities. In addition to sector-specific indices, five size \& style indices are also examined such as small-cap resources, medium-cap resources, small-cap industrials, mid-cap industrials, and small ordinaries. The data for all the indices with daily frequency is downloaded from Global Financial Database website.

The start date is the year from which the daily data for a particular index is available in Global Financial Database website. The index returns for Mondays and Fridays have been calculated as $\ln (\mathrm{pt} / \mathrm{pt}-1) \times 100$ closing to closing prices of each day. The Weekend Effect is calculated as the difference between Friday's return and the next week Monday's return. Monday is the first 3- I have re-run the results by excluding the year 2008, being a peak of GFC. However, the results remain qualitatively similar.

174 January-June $2019 \quad$ Volume $17 \quad$ Number 12 JISR-MSSE


and Friday is the last trading day-of-the-week. The p-values for examining the mean (median) difference between the last and first trading day returns calculated through t-test (signed-rank test) are displayed in parenthesis.

Table 3: Sector and Size Indices Returns

\begin{tabular}{|c|c|c|c|c|c|}
\hline \multicolumn{6}{|c|}{ Panel A: Mean Sector Indices Returns and p-values } \\
\hline & Indices & Start Date & Monday & Friday & Weekend \\
\hline \multirow[t]{2}{*}{ ASX 200 Energy Index } & 1994 & Mean & 0.0998 & 0.0623 & -0.0375 \\
\hline & & p-value & $(0.0013)$ & $(0.1133)$ & $(0.2928$ \\
\hline \multirow[t]{2}{*}{ ASX 200 Retail Index } & 1994 & Mean & 0.0090 & 0.0087 & -0.0003 \\
\hline & & p-value & $(0.1823)$ & $(0.9254)$ & $(0.6565)$ \\
\hline \multirow[t]{2}{*}{ ASX 200 Financial Index } & 2000 & Mean & -0.0190 & -0.0135 & 0.0055 \\
\hline & & p-value & $(0.6362)$ & $(0.7462)$ & $(0.7631)$ \\
\hline \multirow[t]{2}{*}{ ASX 200 Health Care Index } & 1994 & Mean & 0.0341 & 0.0814 & 0.0473 \\
\hline & & p-value & $(0.3819)$ & $(0.0400)$ & $(0.4158)$ \\
\hline \multirow[t]{2}{*}{ ASX 200 Industrials Index } & 1994 & Mean & 0.0478 & -0.0071 & -0.0549 \\
\hline & & $\mathrm{p}$-value & $(0.0038)$ & $(0.7996)$ & $(0.2077)$ \\
\hline \multirow[t]{2}{*}{ ASX 200 Materials Index } & 1994 & Mean & 0.0867 & 0.0890 & 0.0023 \\
\hline & & $\mathrm{p}$-value & $(0.0378)$ & $(0.0546)$ & $(0.9740)$ \\
\hline \multirow[t]{2}{*}{ ASX 200 Telecom Index } & 1996 & Mean & 0.0437 & -0.0032 & -0.0469 \\
\hline & & $\mathrm{p}$-value & $(0.3761)$ & $(0.9346)$ & $(0.5490)$ \\
\hline \multirow[t]{2}{*}{ ASX 200 Transportation Index } & 1994 & Mean & 0.0363 & 0.0018 & -0.0345 \\
\hline & & $\mathrm{p}$-value & $(0.1044)$ & $(0.6284)$ & $(0.5718)$ \\
\hline \multirow[t]{2}{*}{ ASX 200 Consumer Staple Index } & 2000 & Mean & 0.0242 & 0.0615 & 0.0373 \\
\hline & & p-value & $(0.8530)$ & $(0.1078)$ & $(0.4961)$ \\
\hline \multirow[t]{2}{*}{ ASX 200 Utilities Index } & 1996 & Mean & 0.0629 & -0.0129 & -0.0758 \\
\hline & & p-value & $(0.0930)$ & $(0.7149)$ & $(0.1752)$ \\
\hline \multicolumn{6}{|c|}{ Panel B: Mean Size \& Style Indices Returns and p-values } \\
\hline \multirow{3}{*}{ ASX - Small Cap Resources } & Indices & Start Date & Monday & Friday & Weekend \\
\hline & 1994 & Mean & 0.0590 & 0.1313 & 0.0723 \\
\hline & & p-value & $(0.0056)$ & $(<.0001)$ & $(0.2769)$ \\
\hline \multirow[t]{2}{*}{ ASX - Mid-Cap Resources } & 1994 & Mean & 0.0476 & 0.1376 & 0.0900 \\
\hline & & p-value & $(0.1114)$ & $(0.0087)$ & $(0.2772)$ \\
\hline \multirow[t]{2}{*}{ ASX - Small Cap Industrials } & 1994 & Mean & -0.0287 & 0.0476 & 0.0763 \\
\hline & & p-value & $(0.3198)$ & $(0.0004)$ & $(0.0402)$ \\
\hline \multirow[t]{2}{*}{ ASX Mid-Cap Industrials } & 1994 & Mean & 0.0011 & 0.0355 & 0.0344 \\
\hline & & p-value & $(0.1441)$ & $(0.0484)$ & $(0.4081)$ \\
\hline \multirow[t]{2}{*}{ ASX Small Ordinaries } & 1994 & Mean & -0.0075 & 0.0804 & 0.0879 \\
\hline & & p-value & $(0.0624)$ & $(<.0001)$ & $(0.0422)$ \\
\hline
\end{tabular}

The evidence of sector indices returns in Panel A of Table 3 reveal no Weekend Effect. Moreover, in some of the sector indices significantly positive Monday (i.e., first trading day of the week) and/or Friday (i.e., last trading day of the week) returns are documented and the level of significance changes across sectors. Hence, it may be argued that the observed Weekend Effect / calendar anomaly in the earlier results is not caused by economic events or sector-specific factors. This evidence confirms the study of Brusa, Liu, \& Schulman (2003).

\begin{tabular}{llll}
\hline JISR-MSSE & Volume 17 & Number 1 & January-June 2019 \\
\hline
\end{tabular}


They observed no Weekend Effect post-1988 period, i.e., 1988-1996 across different industry/sector indices and broad indices like Dow Jones and NYSE composite in the US market.

However, in Panel B of Table 3, two out of three small-cap size and style indices have a strong Weekend Effect. The ASX small-cap industries and ASX small Ordinaries Index has pronounced positive Weekend Effect. This again suggests that as size of firms gets bigger, the Weekend Effect diminishes. More importantly, the significantly negative first trading day of the week (i.e., Monday) and positive last trading day of the week (i.e., Friday) returns begins to lessen with growth in the size of firm. The connection between firm size and weekend effect is investigated in the following sub-section.

\section{Firm Size and the Weekend Effect}

To test the association between the Weekend Effect / calendar anomaly and the firm size, first, all the ASX firms are grouped into five portfolios according to their market value (size) of every year in the study period, following the Brusa et al. (2000) methodology. The firms that belongs to first quintile portfolio are small and the firms that constitutes fifth quintile portfolio are the large ones. Each year from 1994 to 2007 is ranked into 20\% average size quintiles and stocks merged into one single portfolio. The same method is applied for the period 2008-2018. The mean returns for first trading day of the week (i.e., either Monday or Tuesday) and last trading day of the week (i.e., either Friday or Thursday) in each of the five size quintile portfolios is measured. In each size portfolio, the Weekend Effect is analysed using t-test to ascertain the significance of Weekend Effect. Panel A of Table 4 illustrates the analysed results.

The average Monday returns display a remarkable trend across different firm sizes. Average returns on Mondays for smaller and medium sized firms (quintiles 1 to 4) are negative and significant but for the largest firms (quintile 5), positively significant average Monday returns are observed. The result is very obvious in Panel A and Panel B (second sub-period) of Table 4; the second sub-period sample results of Panel B reveal that the Weekend Effect has completely dissipated in medium and large size firms in the recent past. Simultaneously, the positive Monday returns suggest that Weekend Effect start to disappear in largest firms rather a weak negative or reverse Weekend Effect is appearing. Further, a look at Friday returns, although always significantly positive throughout the study's full-sample period and the sub-periods; the magnitude of average Friday percentage returns decreases with the size of the firm.

The results in both the Panels B and C display that as the firm size expands the average Weekend Effect decreases and this shows the steady shift of average Monday returns (Monday Effect) from significantly negative for smallest firms to significantly positive for the large sized firms; and declining mean positive returns on Fridays. Surprisingly, Panel D shows the weekend effect is weakly significant for smallest capitalized firms at $10 \%$ level and strongly significant weekend effect for large capitalized firms. Thus the evidence is consistent with broad literature showing disappearance and subsequent emergence or even reversal of trading / calendar anomaly. 
The daily average return (in percentage) for Mondays, Fridays of the week and Weekend Effect from January, 1994 to September 30, 2018 for ASX-listed stocks (portfolios are ranked by size and averaged each year (the first quintile comprises smallest firms and the fifth quintile consists of largest firms).

Table 4: Firm Size Effects

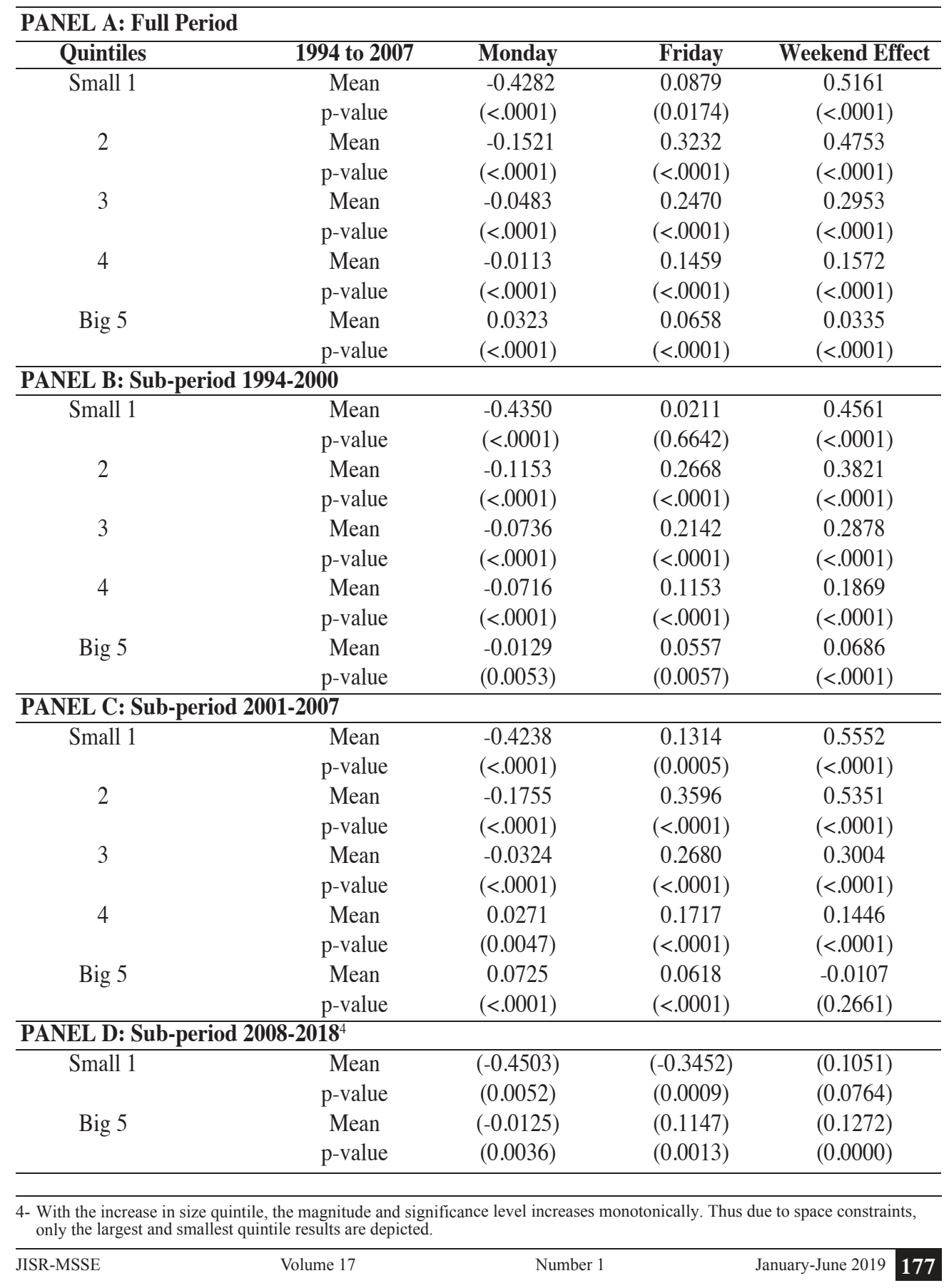


Hence a strong negative relationship is observed between size of firm and calendar anomaly (i.e., weekend effect) from 1994 to 2007 and a weakly significant positive association is documented between size of the company and weekend effect for post-GFC period. The evidence confirms the results of Brusa et al. (2000) and Keim \& Stambaugh (1984). Keim \& Stambaugh (1984) documented Weekend Effect differs across firm size; in particular, for AMEX and NYSE stocks from 1963 to 1979, the average Friday returns are higher for equal-weighted index (that gives equal weight to all firms) than value-weighted index (which assigns higher weight to large capitalized firms), but the average negative Monday returns are same for both the indices. Whereas, in this study on Australian stock exchange, the mean Monday returns varies with the firm size (i.e., from significantly negative returns for smaller firms to significantly positive returns for larger firms) but the Friday returns remain significantly positive across different size portfolios. However, in the recent 10-year data, the Friday returns also shows significant negative returns and contradicts the study of Brusa et al. (2000) for recent data.

Besides, Abraham \& Ikenberry (1994) who study the US market feel that trading strategy of retail traders is one of the causes for this weekend trend. The individual investors usually participate actively on Mondays especially followed by bad news in the capital market. Hence the results in Australian Stock Exchange (ASX) lead to the same explanation for equally-weighted index returns as retail traders are relatively more active in small and medium-size firms.

In order to probe further, the firm size phenomenon, as significant Weekend Effect in the largest quintile portfolio still exist for the whole study period (Panel A of Table 4) and first sub-period (Panel B of Table 4); therefore, the largest quintile of full study sample and two sub-period portfolios of Table 4 is grouped/ranked into further five equal size portfolios ${ }^{5}$.

The daily average return (in percentage) for Mondays, Fridays and Weekends from January, 1994 to December 31, 2007 for ASX (portfolio are ranked by size by dividing the largest quintile of Table 5 into further five equal portfolios (the first quintile refers to the smallest firms and the fifth quintile refers to the largest stocks- within the largest quintile)

Table 5: Largest Firm Size Returns

\begin{tabular}{ccccc}
\hline \multicolumn{5}{l}{ PANEL A: Quintiles of Large Cap stocks (Big 5) } \\
\hline Quintiles & 1994 to 2007 & Monday & Friday & W.E. Effect \\
\hline Small 1 & Mean & -0.0036 & 0.1052 & 0.1088 \\
& p-value & $(0.0506)$ & $(<.0001)$ & $(<.0001)$ \\
2 & Mean & 0.0179 & 0.0753 & 0.0574 \\
& p-value & $(0.5920)$ & $(<.0001)$ & $(0.0030)$ \\
3 & Mean & 0.0703 & 0.0747 & 0.0044 \\
& p-value & $(<.0001)$ & $(<.0001)$ & $(0.8007)$ \\
4 & Mean & 0.0385 & 0.0450 & 0.0065 \\
& p-value & $(0.0162)$ & $(0.0125)$ & $(0.6944)$ \\
Big 5 & Mean & 0.0563 & 0.0320 & -0.0243 \\
& p-value & $(<.0001)$ & $(0.0078)$ & $(0.0995)$ \\
\hline
\end{tabular}

5- Since it is mentioned earlier in the paper that the majority of the stocks traded/listed in the Australian market comprises of small capitalized firms. Hence it is desirable to group the largest firm size quintile into further five equal parts to verify the firm size effects.

178 January-June $2019 \quad$ Volume $17 \quad$ Number $1 \quad$ JISR-MSSE




\begin{tabular}{ccccc}
\hline PANEL BSub-period 1994-2000: Quintiles of Large Cap stocks & (Big 5) & \\
\hline Quintiles & 1994 to 2007 & Monday & Friday & W.E. Effect \\
\hline Small 1 & Mean & -0.0921 & 0.1015 & 0.1936 \\
& p-value & $(<.0001)$ & $(0.0002)$ & $(<.0001)$ \\
2 & Mean & -0.0338 & 0.0657 & 0.0995 \\
& p-value & $(<.0001)$ & $(0.1631)$ & $(0.0021)$ \\
3 & Mean & -0.0174 & 0.0700 & 0.0874 \\
& p-value & $(0.1739)$ & $(0.0167)$ & $(0.0031)$ \\
4 & Mean & 0.0269 & 0.0314 & 0.0045 \\
\multirow{2}{*}{ Big 5 } & p-value & $(0.7247)$ & $(0.6466)$ & $(0.8759)$ \\
& Mean & 0.0639 & 0.0220 & -0.0419 \\
PANEL BSub-period 2001-2007: Quintiles of Large Cap stocks & $($ Big 5) & $(0.4355)$ & $(0.0930)$ \\
\hline \multirow{2}{*}{ Small 1 } & Mean & 0.0732 & 0.1009 & 0.0277 \\
& p-value & $(0.0027)$ & $(<.0001)$ & $(0.2652)$ \\
2 & Mean & 0.0554 & 0.0924 & 0.0370 \\
& p-value & $(0.0093)$ & $(<.0001)$ & $(0.1190)$ \\
3 & Mean & 0.0972 & 0.0638 & -0.0334 \\
& p-value & $(<.0001)$ & $(<.0001)$ & $(0.1188)$ \\
4 & Mean & 0.0588 & 0.0636 & 0.0048 \\
& p-value & $(0.0002)$ & $(<.0001)$ & $(0.8126)$ \\
Big 5 & Mean & 0.0454 & 0.0386 & -0.0068 \\
& p-value & $(<.0001)$ & $(0.0002)$ & $(0.7118)$ \\
\hline
\end{tabular}

The results from data analysis are presented in Table 5. A very clear picture is revealed, that is, with the expansion in firm size, the Weekend Effect starts to dissipate and a significantly weak negative / reverse Weekend Effect starts to emerge. Hence, it may be mentioned that in ASX market, the largest-capitalized firms demonstrate the absence of Weekend Effect that confirms the results of value weighted portfolio / index in Table 2. However, the daily data from 2008 to 2018 shows a reverse picture, whereby small firms depict weak weekend effect and large-cap firms depict stronger weekend effect. The evidence extends some credence to Efficient Market Hypothesis.

Figure 1: Weekend Effect in size quintilies

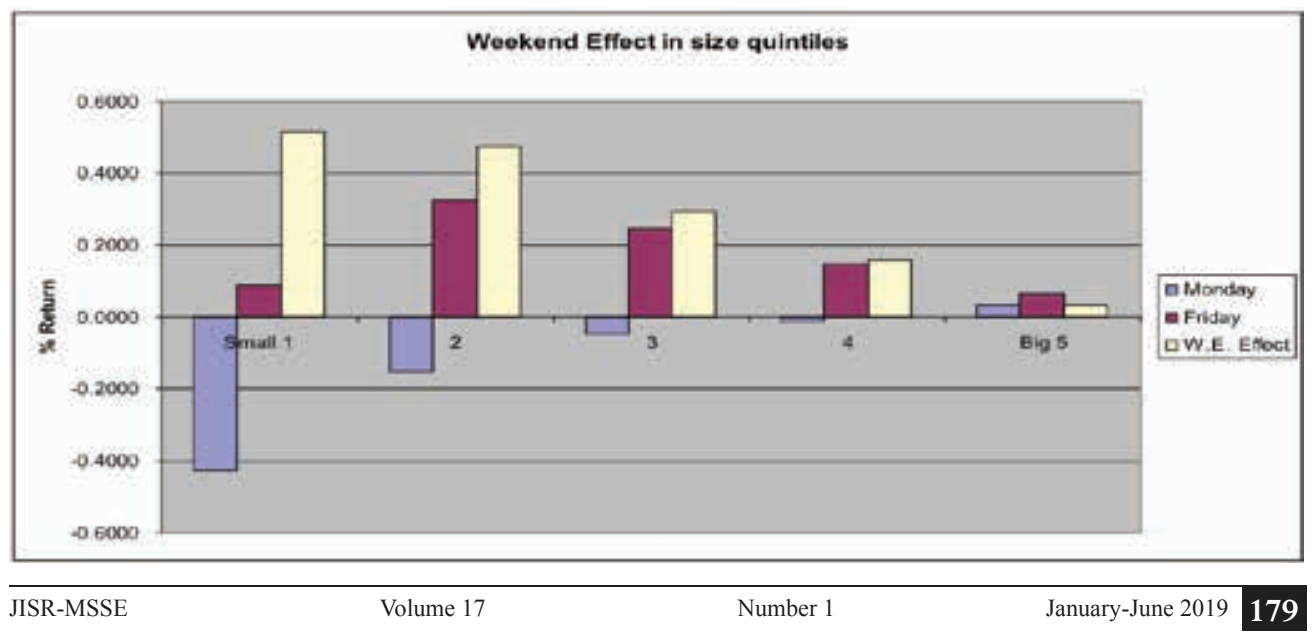


The Monday return, Friday return and Weekend Effect relationship with firm size can be best illustrated in Figure 1. It can clearly be observed that with the growth in the size of firm or when the firm size portfolio increases, the magnitude of mean returns for Friday, Monday and Weekend Effect also decreases and seems to be correlated cross-sectionally to scale of firm operations. But the recent data, not shown in the Figure 1, shows reversal of Weekend effect which increases for large capitalized firms and decreases for small-cap securities.

\section{CONCLUSION}

This research study primarily investigates the presence of calendar anomaly / Weekend Effect anomaly documented in the literature for the Australian financial exchange. The paper finds statistically strong Weekend Effect in stock returns for equal-weighted index for the study period of January 1994 through December 2007 - whereby mean returns for Friday are significantly positive and mean returns for Monday are significantly negative. But the study does not find the Weekend Effect in security returns for value-weighted index. Similarly, for the post GFC period of January 2008 through September 2018, the weekend effect is absent for both equal- and value-weighted indices. The difference between returns on last trading day of the week (i.e., either Friday or Thursday) and the coming first trading day of the week (i.e., either Monday or Tuesday) or Friday returns minus the next week Monday returns is called the Weekend Effect.

These results of this paper provide food for thought regarding the assumed association between the Weekend Effect and the size of firm in the Australian equity market. After sorting stocks into quintiles according to market capitalization, the study shows an 'established' Weekend Effect for small-cap securities and a reverse / negative Weekend Effect for large-cap securities for the period from 1994 till 2007. But the Weekend Effect becomes weak for small-capitalized firms and significantly strong for large-capitalized firms for the extended period from 2008 to 2018. Moreover, Monday's returns for small-capitalized stocks tend to be significantly negative, but Monday's returns for large-capitalized stocks are significantly positive. Thus the evidence demonstrates a strong Weekend Effect for small-cap securities for the earlier period and weak Weekend Effect for the later period of the study. Conversely, a reverse / negative Weekend Effect is documented in large-capitalized securities for the earlier period and strong Weekend Effect for the large-sized firms over the recent extended sample period examined.

Therefore, the results of this study during the period from 1994 to 2007 confirms the findings of Keim \& Stambaugh (1984) and Gibbons \& Hess (1981), who documented stronger calendar anomaly / Weekend Effect in small companies in comparison to large companies. Besides, the findings of negative or reverse or negative Weekend Effect (i.e., calendar anomaly) in large-capitalized stocks confirms the results of Brusa et al. (2000), who detect a 'reverse' Weekend Effect that is limited to the largest firms' portfolios, as an unconventional finding in the literature. However, during the period from 2008 to 2018, the evidence is in conformity with Olson et al. (2015) who finds disappearance of trading anomaly and its subsequent re-emergence and even reversals. This study also documents that Weekend Effect has shifted from small firms to large sized companies. Lastly, the disappearance of weekend effect and its shift from small firms in earlier sample period to large firms in the recent past does not negate the efficient capital markets hypothesis. 


\section{REFERENCES}

Abraham, A., \& Ikenberry, D. L. (1994). The Individual Investor and the Weekend Effect. The Journal of Financial and Quantitative Analysis, 29(2), 263-277.

Akbalik, M., \& Ozkan, N. (2017). Day of the Week Effect in the Stock Markets of Fragile Five Countries After 2008 Global Financial Crisis. Global Financial Crisis and Its Ramifications on Capital Markets, Springer International Publishing, pp. 507-518.

Blau, B. M., Ness, B. F. V., \& Ness, R. A. V. (2009). Short Selling and the Weekend Effect for NYSE Securities. Financial Management, 38(3), 603-630.

Board, J. L. G., \& Sutcliffe, C. M. S. (1988). The Weekend Effect in UK Stock Market Returns. Journal of Business Finance \& Accounting, 15(2), 199-213.

Brusa, J., Liu, P., \& Schulman, C. (2000). The Weekend Effect, 'Reverse' Weekend Effect, and Firm Size. Journal of Business Finance \& Accounting, 27(5/6), 555.

Brusa, J., Liu, P., \& Schulman, C. (2003). The Weekend and 'Reverse' Weekend Effects: An Analysis by Month of the Year, Week of the Month, and Industry. Journal of Business Finance \& Accounting, 30(5/6), 863-890.

Caporale, G. M., Gil-Alana, L. A., \& Plastun, A. (2016). The weekend effect: an exploitable anomaly in the Ukrainian stock market? Journal of Economic Studies, 43(6), 954-965.

Chen, H., \& Singal, V. (2003). Role of Speculative Short Sales in Price Formation: The Case of the Weekend Effect. The Journal of Finance, 58(2), 685-705.

Chkir, I., Chourou, L., Rahman, A., \& Saadi, S. (2014). Econometric Fragility of Market Anomalies: Evidence from Weekday Effect in Currency Markets. Quarterly Journal of Finance and Accounting, 52(3/4), 75-117.

Christophe, S. E., Ferri, M. G., \& Angel, J. J. (2004). Short-Selling Prior to Earnings Announcements. The Journal of Finance, 59(4), 1845-1876.

Christophe, S. E., Ferri, M. G., \& Angel, J. J. (2009). Short selling and the weekend effect in Nasdaq stock returns. Financial Review, 44(1), 31-57.

Connolly, R. A. (1989). An Examination of the Robustness of the Weekend Effect. The Journal of Financial and Quantitative Analysis, 24(2), 133-169.

Davidson, S., \& Faff, R. (1999). Some additional Australian evidence on the day-of-the-week effect. Applied Economics Letters(6), 247-249.

Dellavigna, S., \& Pollet, M. J. (2009). Investor Inattention and Friday Earnings Announcements. The Journal of Finance, 64(2), 709-749.

Fama, E. F. (1970). Efficient Capital Markets: A Review of Theory and Empirical Work. The Journal of Finance, 383-417.

Fama, E. F., \& French, K. R. (1988). Permanent and Temporary Components of Stock Prices. The Journal of Political Economy, 96(2), 246-273.

Fama, E. F., \& French, K. R. (1992). The Cross-Section of Expected Stock Returns. The Journal of Finance, 47(2), 427-465.

Fama, E. F., \& French, K. R. (1993). Common risk factors in the returns on stocks and bonds. Journal of Financial Economics, 33(1), 3-56.

French, K. R. (1980). Stock Returns and the Weekend Effect. Journal of Financial Economics, 8(1), 55-69.

Gao, P., Hao, J., Kalcheva, I., \& Ma, T. (2015). Short sales and the weekend effect-Evidence from a natural experiment. Journal of Financial Markets, 26(1), 85-102.

Gibbons, M. R., \& Hess, P. (1981). Day of the Week Effects and Asset Returns. The Journal of Business, 54(4), 579-596. 
Rossi, M., \& Gunardi, A. (2018). Efficient market hypothesis and stock market anomalies: Empirical evidence in four European countries. The Journal of Applied Business Research, 34(1), 183-192.

Jaffe, J., \& Westerfield, R. (1985). The Week-End Effect in Common Stock Returns: The International Evidence. Journal of Finance, 40(2), 433-454.

Keim, D. B. (1989). Trading Patterns, Bid-Ask Spreads, and Estimated Security Returns. Journal of Financial Economics, 25(1), 75-97.

Keim, D. B., \& Stambaugh, R. F. (1984). A Further investigation of the Weekend Effect in Stock Returns. The Journal of Finance, 39(3), 819-835.

Lakonishok, J., \& Maberly, E. (1990). The Weekend Effect: Trading Patterns of Individual and Institutional Investors. The Journal of Finance, 45(1), 231-243.

Malkiel, B. G. (2003). The Efficient Market Hypothesis and Its Critics. The Journal of Economic Perspectives, 17(1), 59-82.

Mehdian, S., \& Perry, M. J. (2001). The Reversal of the Monday Effect: New Evidence from US Equity Markets. Journal of Business Finance \& Accounting, 28(7\&8), 1043-1065.

Olson, D., Mossman, C., \& Chou, N. T. (2015). The evolution of the weekend effect in US markets. The Quarterly Review of Economics and Finance, 58, 56-63.

Yakob, N. A., Beal, D., \& Delpachitra, S. (2005). Seasonality in the Asia Pacific stock markets. Journal of Asset Management, 6(4), 298-318. 